\title{
Precarização do trabalho e o processo de derrocada do trabalhador ${ }^{1}$
}

\author{
Marley Rosana Melo de Araújo, Kátia Regina Santos de Morais \\ Universidade Federal de Sergipe (São Cristóvão, SE)
}

\begin{abstract}
As mudanças globais vivenciadas atualmente fomentam um novo paradigma nas relações trabalhistas, a exemplo de formas precarizadas de trabalho e emprego, que por sua vez têm sido percebidas, a partir da proliferação das novas modalidades de contrato e do declínio da oferta de empregos típicos/permanentes, como uma das consequências mais visíveis da flexibilização do mercado de trabalho. Este artigo tem por objetivo apresentar os aspectos caracterizadores da precarização do trabalho e suas consequências para o trabalhador. A precarização, em suma, apresenta-se como um fenômeno que perpassa o dinâmico movimento de estruturação do trabalho e do emprego, posto que concerne tanto ao crescimento do desemprego e à ampliação do exército de reserva quanto às especificidades dos empregos disponíveis no mercado de trabalho, enfatizados pela instabilidade e efemeridade contratuais. Isso conduz à expansão do contingente de trabalhadores alienados de seus direitos e sujeitos a condições de trabalho instáveis, insatisfatórias e potencialmente adoecedoras.
\end{abstract}

Palavras-chave: Trabalho, Precarização, Relações trabalhistas.

Labor precariousness and the worker's overthrow process

Current global changes foster a new paradigm in labor relationships, such as precarious forms of work and employment, which have been perceived, from the proliferation of new contract modalities and the decline of typical/permanent employment, as one of the most visible consequences of labor market flexibility. This article aims to present the characterizing aspects of work precariousness and its consequences for the worker. In short terms, precariousness is a phenomenon that runs through the dynamic movement of work and employment structuring, as it concerns not only to unemployment growth and the expansion of the reserve register but also to the specificities of the jobs available in the labor market, emphasized by the instability and contractual ephemerality. It leads to an increasing number of workers who are alienated from their rights and subjected to unstable, unsatisfactory and potentially ill conditions of labor.

Keywords: Labor, Precariousness, Labor relationships.

\section{Introdução}

$\mathrm{D}$ esde a reorganização política, econômica e social que ocorreu na Idade Contemporânea e, principalmente, a partir do século XX, o trabalho tornou-se categoria importante na construção da identidade do sujeito, sendo estruturante tanto para a sociedade quanto para o indivíduo (Borges \& Yamamoto, 2004). Ele é um determinante central na manutenção da saúde do trabalhador, uma vez que se reflete em posição socioeconômica, socialização de adultos, desenvolvimento da identidade e autoestima e amplia possibilidades de conectividade social e participação em redes sociais fora da família (LaMontagne, 2010).

O trabalho é considerado objeto de estudo diverso, ambíguo e complexo, sendo um aspecto da vida que medeia a integração social através do valor econômico e cultural intrínseco, o que explica sua importância no que concerne à saúde física e mental das pessoas (Leal, 2008). Nessa perspectiva, o trabalho é elemento salutar no desenvolvimento individual e social. No entanto, apesar de promover contribuições no que tange a metas pessoais e de colaborar na constituição de identidade do trabalhador como sujeito inserido em um determinado contexto social, o trabalho

1 Este trabalho recebeu apoio financeiro na forma de bolsa de iniciação científica Copes-UFS, concedida à segunda autora, a qual foi orientada pela primeira. 
também pode ser prejudicial, seja pela exposição a riscos físicos, químicos e/ou psicológicos ou pela privação material e a posição socioeconômica desfavorecida, provenientes de baixa renda e de salários insatisfatórios. Por esse ângulo, o trabalho é aspecto pernicioso e fonte de experiências de sofrimento. Essa faceta do trabalho tende a comprometer, principalmente, indivíduos menos favorecidos financeiramente, os quais dispõem de poucos recursos materiais e sociais para atenuar os impactos das más condições laborais (LaMontagne, 2010).

Observa-se ainda que os trabalhadores que reúnem menos benefícios financeiros e proteção social estão mais expostos às modificações na legislação e práticas trabalhistas, sendo desfavorecidos nos diversos âmbitos da vida, como saúde, educação, moradia, transporte, ainda que trabalhadores que ocupem empregos de alto status ou que possuam alta escolaridade também possam experimentar condições de trabalho precarizadas (LaMontagne, 2010; Tosta, 2008).

Com a globalização dos mercados e do capital e o acirramento da concorrência internacional entre empresas, a pressão para a minimização do custo do trabalho leva à compressão do número de trabalhadores efetivos e à externalização de um número crescente de tarefas, bem como à deslocalização de tarefas e de empresas para zonas com salários mais baixos. Isso implica a redução do emprego estável e o aumento de uma força de trabalho flexível, que se encontra em condições precárias e pouco ou nada protegidas (Kovács, 2003). A precarização do trabalho é elemento central da nova dinâmica do desenvolvimento do capitalismo, criando uma nova condição de vulnerabilidade social: um processo social que modifica as condições de trabalho (assalariado e estável), anteriormente hegemônicas no período da chamada sociedade salarial ou fordista (Druck, 2011). Esse mecanismo faz do trabalho o principal fator de ajustamento para a competição internacional. É anunciada a redução drástica, até a extinção do emprego estável, a tempo integral, a favor do emprego flexível. Essa evolução implica o aumento da força de trabalho flexível, fluida, periférica ou contingente que engloba, sobretudo, os trabalhadores a tempo parcial, temporariamente contratados, e certas categorias dos trabalhadores por conta própria (Kovács, 2003). O conteúdo dessa precarização comparece na condição de instabilidade e de insegurança, no imperativo de adaptabilidade, na fragmentação dos coletivos de trabalhadores e no esvaimento do conteúdo social do trabalho. Essa nova condição de trabalho, paulatinamente, se torna central e hegemônica, antagonizando com outras formas de trabalho e de direitos sociais que ainda permanecem e resistem (Druck, 2011).

A precarização do trabalho, portanto, tem sido percebida como uma das consequências mais visíveis da flexibilização do mercado de trabalho, que preconiza a proliferação de formas de emprego de caráter flexível, das novas formas de contrato e do declínio da oferta de empregos típicos/permanentes. Este artigo tem por objetivo apresentar os aspectos caracterizadores da precarização do trabalho e suas consequências para o trabalhador. Nesse cenário de transformação constante, são prementes estudos que versem sobre os impactos das novas formas de emprego com vistas a ampliar a compreensão sobre o tema (especialmente no tocante à saúde física e psicológica do trabalhador, que subjaz às condições precarizadas de emprego), bem como contribuir para o desenvolvimento de iniciativas que visem atenuar os impactos da vivência da precarização sobre os indivíduos.

\section{Condicionantes da precarização do trabalho}

Após a Revolução Industrial, iniciada no século XVIII, a atividade laboral passou a ser observada de modo mais objetivo e sistemático em virtude do crescimento acelerado dos novos centros urbanos e da necessidade de sustentar um padrão de produção, tornando-se uma preocupação para os Estados recém-estabelecidos sob os moldes do regime capitalista em ascensão. As atividades 
econômicas eminentemente artesanais, predominantes até então, foram suplantadas pelo modo de produção fabril em escala, amparado pela força de trabalho constituída por homens livres - e também por mulheres e crianças - compelidos a sujeitarem-se a jornadas de trabalho exaustivas sob parcas condições de salubridade, dada a necessidade de garantir moradia e alimentação (Huberman, 1986).

A mecanização do trabalho preconizada pelo taylorismo (que introduziu o modo de organização fabril ao postular o desenvolvimento dos métodos e organização do trabalho visando controlar o tempo dedicado a determinada atividade) e continuada pelo fordismo (que aprimora o sistema predecessor ao introduzir o conceito de linha de montagem e, com isso, propõe uma nova dinâmica ao trabalho) fez com que o trabalhador perdesse progressivamente o controle sobre o processo produtivo, visto que a divisão do trabalho, introduzida pelo sistema de fábrica, significou uma separação extrema entre concepção e execução do trabalho (Navarro \& Padilha, 2007), fragilizando a representação que o trabalhador tinha acerca de sua atividade, bem como do seu papel na sociedade de forma geral.

Durante o século XIX, após a sedimentação do modo capitalista de produção, difundiu-se a ideia de que a riqueza de um país dependia do trabalho. Desse modo, o trabalho é deslocado de um âmbito relativamente secundário em outras épocas, cujos objetivos eram apenas ocupar o tempo e garantir a subsistência sem maiores ambições em longo prazo e em nível macro, e passa a ocupar um papel de fundamental importância, já que agora concentra não apenas propósito existencial, como também a dedicação de grande parte do tempo de vida de um indivíduo (Kubo \& Gouvêa, 2012).

No que diz respeito ao trabalho na contemporaneidade, especialmente no que tange às últimas décadas do século XX e o início do XXI, a concepção de trabalho e a forma como ele é vivenciado são permeadas, principalmente, pelas premissas do pós-fordismo (ou toyotismo), um paradigma que prima por uma produção descentralizada e em pequenos lotes, flexibilizada através da automação e da prática de diferentes modalidades de contrato de trabalho, a fim de alcançar um patamar superior de qualidade e produtividade, em detrimento da produção de bens padronizados e em larga escala (Antunes, 2011). Com uma doutrina pautada pela acumulação flexível, pela empresa enxuta, pela implantação de programas de qualidade total e técnicas japonesas de gestão, além da introdução de programas de participação nos lucros e resultados, e sob uma pragmática que se adequava fortemente aos desígnios do capital financeiro e do ideário neoliberal, foi possível uma reestruturação produtiva que teve como consequências a ampliação da flexibilização, informalidade e precarização da classe trabalhadora (Antunes, 2014).

Desde então, convivemos com modalidades da precarização próprias da fase da flexibilidade toyotizada, com seus traços de continuidade e descontinuidade em relação ao modo de produção taylorista-fordista (Antunes, 2011). Os imperativos da flexibilidade manifestam-se na difusão de uma grande variedade de arranjos: flexibilidade em termos contratuais, da jornada de trabalho, de espaço e de estatutos do trabalho (trabalho a tempo parcial, trabalho no domicílio, trabalho independente, trabalho temporário, teletrabalho, entre outros) (Kovács, 2003), flexibilidade do processo produtivo, da estrutura de poder nas organizações, das relações trabalhistas (Leite, 2003). Além dos imperativos de flexibilidade exigidos pelo modo de produção toyotista, também mudam as relações entre as empresas. A intensificação e a generalização das práticas pós-fordistas de gestão do trabalho desencadearam um processo de terceirização, levando a uma proliferação de micro e pequenas empresas que utilizam contratos precários de trabalho, embora tal prática não seja privativa de empresas terceirizadas. A rede de fornecedores e de terceirizados trabalha para as grandes corporações criando uma gestão da produção mais horizontalizada, mas gerando um estatuto de dependência e fidelidade para as terceirizadas (Druck, 1999).

O toyotismo, ou modelo de acumulação flexível, é marcado por uma profunda segmentação do mercado de trabalho. Isso acarreta uma significativa diferença em relação às condições de trabalho entre os trabalhadores estáveis, que constituem o núcleo da força de trabalho, e os 
trabalhadores periféricos, terceirizados ou temporários. Também há diferença entre a porcentagem de trabalhadores que pertencem ao núcleo ou à periferia da força de trabalho (Leite, 2003), com grande preponderância dessa última em várias cadeias de negócios. As práticas de organização flexível do trabalho têm redefinido os locais de trabalho, constituídos por trabalhadores qualificados (valorizados pelo seu saber técnico) e por trabalhadores sem qualificação (subcontratados com baixos salários). A focalização na atividade central implica a existência de um número reduzido de empregos bem pagos, estáveis e com perspectivas de desenvolvimento profissional; para esse segmento de trabalhadores, a empresa constituiria, em tese, um lugar de cidadania, de sociabilidade, de expressão e de subjetividade. Contudo, quem faz parte hoje da força de trabalho nuclear, não está isento da ameaça de amanhã passar para a força de trabalho periférica ou contingente, cuja principal característica é não saber onde e quando encontrará o seu próximo emprego. A inconstância, ou seja, a "estabilidade da insegurança" tende a tornar-se modo de vida (Kovács, 2003).

Com a desestruturação crescente do Estado de bem-estar social nos países industriais desenvolvidos, e com a ampliação do desemprego estrutural, os capitais transnacionais implementam alternativas de trabalho crescentemente desregulamentadas e informais, de que são exemplo as existentes formas de terceirização (Antunes \& Alves, 2004). Barreto (2003) concebe a precarização do trabalho como resultado da expansão das atividades capitalistas decorrente da crise do fordismo e do Estado de bem-estar social a partir dos anos 1970. Com a implementação dos processos de reestruturação produtiva e aplicação de políticas neoliberais, "o mundo do trabalho passa a ser regido cada vez mais pelas oscilações de mercado, e para tanto, é necessário que indústrias e empresas prestadoras de serviços tenham maior flexibilidade de contratação e demissão de pessoal" (Aquino, Moita, Correa \& Souza, 2014, p. 177).

Dessa forma, a diminuição da oferta de empregos típicos ou permanentes, de tempo integral, faz com que a força de trabalho excedente do mercado formal eventualmente passe a compor estatísticas do mercado informal, uma vez que os trabalhadores que perdem seus empregos no setor formal são, muitas vezes, compelidos, por pressões financeiras (já que as garantias concedidas pelo Estado para o contingente de indivíduos desempregados são disponibilizadas por um curto período de tempo), a adentrar o setor informal e, portanto, permanecerem sem acesso a benefícios e direitos versados pela lei. Embora possa haver um período de latência entre a transição do mercado formal para o informal, este último absorve parte da força de trabalho excludente do setor formal regido por normas trabalhistas e direitos constitucionais, operando como uma reserva de indivíduos à margem do que preconizam as normas trabalhistas.

Nesse ínterim, a precarização do trabalho tomará um lugar cativo na dinâmica de flexibilidade engendrada pelas novas forças produtivas e econômicas do capital, por mais que a crescente flexibilidade do mercado de trabalho signifique a expectativa de transferência de riscos e custos sociais do trabalho dos empregadores para os indivíduos e para o Estado (Kovács, 2003). Segundo Costa e Tambellini (2009, p. 954), "os empregos precários já não resultam da ausência de crescimento econômico, mas são inerentes ao próprio modelo de crescimento". Em muitos países em desenvolvimento, o emprego precário não é apenas o resultado de uma implacável, quase mecânica, mudança de "segurança" para "flexibilidade", mas uma parte essencial da estratégia de desenvolvimento afiançada pelo Estado (Lee \& Koffman, 2012).

É nesse contexto, caracterizado por um processo tendencial de precarização estrutural do trabalho, que os capitais globais estão exigindo também o desmonte da legislação social protetora do trabalho, uma vez que os direitos ligados ao trabalho e à proteção social são entendidos como obstáculos à competitividade. Segurança social, regulação do mercado de trabalho, forte presença de sindicatos são apontadas como as principais causas de dificuldades econômicas em épocas de crise global (Kóvacs, 2003). Contudo, flexibilizar essa legislação social significa ampliar as formas de precarização e rechaçar os direitos sociais que foram arduamente conquistados pela classe 
trabalhadora desde o início da Revolução Industrial, na Inglaterra, e especialmente pós-1930, quando se toma o exemplo brasileiro (Antunes, 2011). A relação precária de trabalho é algo que dificulta a capacidade de organização da classe trabalhadora e legitima, pela via da fragmentação, o poder do capital sobre o trabalho (Costa \& Tambellini, 2009).

Os diversos mecanismos de flexibilização do trabalho têm sido importante instrumental utilizado pelas empresas para burlar a legislação social do trabalho (Antunes, 2014). As formas precárias de trabalho e de emprego, expressas na reestruturação do mercado de trabalho, o papel do Estado e sua (des) proteção social, as práticas gerencialistas de organização do trabalho e o esvaziamento da força sindical estão indissociavelmente articulados (Druck, 2011) nessa dinâmica liberal de modernização do processo produtivo para fins de acomodação aos interesses do capital financeiro, embora um dos produtos dessa fórmula seja a generalização de uma altíssima vulnerabilidade social e política.

A partir de 1990, no que tange ao desenvolvimento das práticas de flexibilização e consequente precarização do trabalho no cenário socioeconômico brasileiro, com a disseminação do neoliberalismo, ampliou-se o processo de reestruturação produtiva mediante adoção de novos padrões organizacionais e tecnológicos e de novas formas de organização do trabalho e da introdução dos métodos participativos, em decorrência das imposições das empresas transnacionais que levaram as suas subsidiárias no Brasil a adotarem técnicas inspiradas no toyotismo e nas formas flexíveis de acumulação (Antunes, 2014). Observa-se um processo de pauperização, inclusive entre os trabalhadores integrados ao mercado de trabalho, como resultado de uma trajetória marcada pela insegurança, instabilidade, salários baixos e precariedade nos vínculos laborais. Essa degradação das condições materiais de vida, agravada pela ausência de mecanismos de proteção social e associada à desestruturação/reconstrução de identidades geradas em torno do trabalho, configura, em sua complexidade, questão social premente (Gomez \& Thedim-Costa, 1999).

As repercussões para a saúde situam-se no cerne dessa problemática que afeta os trabalhadores ainda inseridos no mercado formal, sobretudo os terceirizados, mas se reflete, particularmente, no grande contingente de excluídos e em segmentos mais vulneráveis do mercado informal, em contínua expansão (Gomez \& Thedim-Costa, 1999). Assim, o aumento do desemprego e da precarização, em interface com a perda dos direitos e baixos salários, são características da atual classe trabalhadora brasileira (Antunes, 2008). As características e vivências dessa classe assemelham-se ao que Standing (2014) definiu como o "precariado" - uma nova classe trabalhadora que convive com incerteza e insegurança crônicas, associadas à casualização, à informalização, ao regime de tempo parcial, ao falso autoemprego. Essa nova classe encontrase exposta a riscos e vulnerabilidades elevados devido à sua trajetória desprotegida em caráter legal e social, sendo baixa a probabilidade de conseguir fazer face a esses riscos ou de vir a recuperar-se deles.

Dessa forma, a precarização do trabalho alastra-se cada vez mais, de modo que a deterioração das formas de emprego está em vias de suplantar o paradigma do emprego homogêneo e estável. Os trabalhadores transformam-se em seres descartáveis, que podem ser substituídos a qualquer momento e sem garantia alguma de retorno quando não atendem ao ritmo do processo produtivo que lhes é exigido. "Transformam-se os homens que trabalham em obsoletos e descartáveis que devem ser 'superados' e substituídos por outros novos e modernos, isto é, flexíveis” (Druck, 2011, p. 43).

\section{Trabalho precário: uma tentativa de rastrear seu conteúdo}

Para Tosta (2008), o modelo normativo de emprego padrão é o trabalho permanente, em tempo integral, com supervisão direta do empregador e acesso do empregado a benefícios sociais, como seguro-desemprego, assistência médica de prevenção a doenças, auxílio a acidentes e aposentadoria. Contudo, a proliferação de formas de emprego flexível e o declínio do emprego permanente de 
tempo integral têm se refletido nas características contratuais de empregos precários (a exemplo de instabilidade no emprego, negociações sobre condições de trabalho em nível individual, baixos salários e privação econômica, direitos trabalhistas e proteção social limitados) e dimensões sociais do ambiente laboral próprias de relações precárias de trabalho, como: relações de poder que assumem a forma de desamparo do trabalhador diante do autoritarismo no contexto laboral, impotência para exercer direitos no local de trabalho, entre outros (Vives et al., 2010).

Nesse sentido, Arnold e Bongiovi (2013) asseveram que não há nenhuma experiência singular no trabalho precário, uma vez que esse fenômeno tem acometido o mercado e a economia tanto de países plenamente industrializados quanto de países em desenvolvimento. Arranjos políticos e esforços de organizações têm sido direcionados para o provimento de força de trabalho maleável que se adapte facilmente às constantes mudanças do cenário mercadológico internacional, visto que, com a redução do proletariado fabril, efetivou-se uma ampliação do setor de serviços a partir de uma subproletarização intensificada, presente na expansão do trabalho parcial, temporário, subcontratado e terceirizado.

Para Antunes (2008), a precarização do trabalho tem caráter estrutural, sendo uma faceta da reestruturação produtiva e organizacional adotada por empresas que visam aumentar seus lucros, a partir do aumento de produtividade da mão-de-obra, ao passo em que se diminui a carga de direitos trabalhistas e o número de postos de trabalho para que haja mais indivíduos à procura de trabalho e dispostos a aceitar, sem contestação, condições precárias de contratação. Tal estratagema do mercado tem pontuado o cenário socioeconômico com estatísticas significativas referentes ao desemprego, uma vez que o mercado tem exigido dos empregados maior qualificação, disponibilidade e multifuncionalidade. O conceito de precarização estrutural do trabalho, defendido por Antunes, indica que o emprego precário é produto das transformações promovidas pelo modelo de acumulação flexível, e que decorre da atribuição de status de empregos socialmente reconhecidos a trabalhos marginalizados, desamparados quanto a benefícios de toda sorte. $\mathrm{O}$ emprego precarizado, por esse viés, caracteriza-se, sobretudo, pela instabilidade, desproteção legislativa e flexibilização contratual.

Por essa perspectiva, entende-se que os empregos de características precárias não são produtos de ausência de crescimento econômico. Pelo contrário, são inerentes ao próprio modelo de desenvolvimento econômico de caráter toyotista, visto que a necessidade de elevação da produtividade motivou novas práticas trabalhistas sob imposição da concorrência internacional, que passou a buscar, além de isenções fiscais, níveis mais rebaixados de remuneração da força de trabalho (Antunes, 2008).

Contudo, a definição, caracterização e postulação de indicadores do que seja trabalho precário ainda é uma tarefa por ser completada no meio acadêmico. Em 1999, a Organização Internacional do Trabalho (OIT) criou os Indicadores de Trabalho Decente, definindo-o como um trabalho produtivo e adequadamente remunerado, exercido em condições de liberdade, equidade e segurança, sem quaisquer formas de discriminação, e capaz de garantir uma vida digna a todas as pessoas que vivem de seu trabalho. Tais indicadores surgiram a partir de um diagnóstico sobre o trabalho na década de 1990, com especial atenção à América Latina. Por contraste, trabalhos precários compreenderiam aqueles portadores de lacunas e/ou deficiências dos elementos qualificadores do trabalho decente. De maneira alarmante, esse diagnóstico indicou que as transformações do trabalho fizeram regredir conquistas significativas, redefinindo o patamar dos direitos sociais e trabalhistas em todo o mundo, inclusive nos países mais desenvolvidos (Druck, 2011).

Partindo desse princípio, Druck (2011) propõe e executa um projeto de pesquisa para a construção dos Indicadores de Precarização Social do Trabalho, a partir de um posicionamento crítico frente à atual realidade de trabalho brasileira. Nessa proposição, de cunho qualitativo e quantitativo, o trabalho precário assume diversas dimensões ou indicadores: comparece nas formas 
de inserção e de contrato, na informalidade, na terceirização, na desregulação e flexibilização da legislação trabalhista, no desemprego, na intensificação do trabalho, no adoecimento, nos acidentes de trabalho, na perda salarial, na fragilidade dos sindicatos e de identidades coletivas.

Um dos indicadores de Druck refere-se à precarização da contratação, a qual é ratificada na sua flexibilização: significa, em função dos interesses empresariais, reduzir o prazo de contratação e adotar formas de contrato que descaracterizam a relação salarial e que, por sua vez, podem acentuar a precarização das condições de trabalho, a partir de maior intensidade na utilização da força de trabalho, através da plurifuncionalidade do trabalhador, o qual passa a executar diversas tarefas em uma jornada de trabalho indeterminada e a ter comprometidos os direitos ao descanso semanal ou anual. Verma e Gomes (2014) recordam que a flexibilização se adequa à demanda de produtos e serviços, tornando o mercado altamente competitivo, de modo a atrair novos investimentos e a fomentar o crescimento econômico de forma geral.

A precarização apresenta-se como um fenômeno que perpassa o dinâmico movimento de estruturação do trabalho e do emprego, posto que concerne tanto ao crescimento do desemprego e ampliação do exército de reserva quanto às especificidades dos empregos disponíveis no mercado de trabalho, enfatizados pela instabilidade e efemeridade contratuais. Desse modo, o aumento do número de trabalhadores que se encontra em situação de emprego precário ou em más condições de trabalho leva à expansão do contingente de trabalhadores alienados de seus direitos e sujeitos a condições de trabalho instáveis e insatisfatórias.

Alguns estudos estão sendo realizados no Brasil para detectar percepção, vivências e consequências da precarização sobre o trabalhador, ainda que tais iniciativas pareçam concentrar-se em certos grupos ocupacionais. Nascimento (2016) investigou a percepção de precarização do emprego com o corpo de enfermagem do único hospital de urgência do estado de Sergipe. Para tanto, aplicou instrumento estruturado (Inventário de Precarização Laboral - Iprel) em 279 profissionais de saúde. A partir de teste estatístico, foram extraídos dois fatores (Higiene Ocupacional e Justiça - HO\&J e Relações de Trabalho - RT) referentes à percepção da amostra sobre o que seriam empregos precários. $\mathrm{O}$ fator Higiene Ocupacional e Justiça abrange aspectos relacionados ao oferecimento, por parte da instituição, de condições de trabalho adequadas e seguras que asseverem a saúde e o bem-estar do colaborador no exercício de suas atividades, bem como contempla a percepção de justiça nas trocas existentes na díade empregador/empregado. Já o fator Relações de Trabalho contempla ideias associadas à gestão de pessoas e às responsabilidades patronais na relação trabalhista, como: reconhecimento profissional, participação na tomada de decisão, respeito aos empregados como seres humanos, atendimento à legislação trabalhista quanto a pagamento de salários, benefícios e filiação ao sindicato. Em síntese, para os participantes do estudo, o emprego precarizado é aquele em que o trabalhador se percebe injustiçado pelas práticas de gestão vivenciadas, sobrecarregado no exercício das suas atividades, sem condições de exercê-las com segurança, prejudicando o seu bem-estar físico e mental. Os escores médios nos fatores demonstraram que os participantes não percebem como adequadas e seguras as condições de trabalho no hospital, nem como justas as trocas existentes na díade empregador/empregado $(\mathrm{M}=1,5 ; \mathrm{DP}=0,52)$, ainda que acusem como razoáveis as práticas de gestão de pessoas e o cumprimento das responsabilidades trabalhistas $(\mathrm{M}=2,0 ; \mathrm{DP}=0,51)$.

$\mathrm{O}$ dado encontrado nessa pesquisa, quanto à baixa percepção por parte dos profissionais de saúde em aspectos de HO\&J, foi ilustrado por Souza et al. (2010) em um estudo que investigou enfermeiros de um hospital universitário do Rio de Janeiro que, em uma conjuntura de precarização das condições de trabalho, necessitavam fazer adaptações nos insumos hospitalares para garantirem o oferecimento dos cuidados, pois os materiais e equipamentos necessários para os atendimentos eram insuficientes, inexistentes e/ou a qualidade era inadequada para o fim a que se destinavam. Para os autores do estudo, a precariedade das condições de trabalho fazia com que o enfermeiro 
experimentasse mais sofrimento que prazer durante a realização de suas atividades laborais, na medida que tinha que prover a ausência de insumos através da adaptação e improvisação de materiais e equipamentos, gerando frustração, irritabilidade, raiva, medo e impotência.

Outra pesquisa (Costa \& Tambellini, 2009) foi realizada com dezoito trabalhadores terceirizados por cooperativa, lotados nos serviços de enfermagem de uma instituição pública federal de saúde no município do Rio de Janeiro. Foi utilizado um questionário qualitativo com o objetivo de identificar a percepção desses profissionais acerca da precarização das suas relações de trabalho e descrever como esses profissionais percebiam as consequências da precarização na sua saúde. Apurou-se que os participantes conheciam seus direitos e garantias sociais, entretanto, entendiam que esses direitos eram desrespeitados devido a uma conjuntura que os tornava impotentes para lutar e desvalorizados como seres humanos. A falta de proteção social, a insegurança e o desrespeito às limitações físicas do seu corpo eram consequências desse processo. $\mathrm{O}$ medo de perder o emprego e as doenças que sobre ele advêm constituiriam reações a essa conjuntura.

Ainda no mesmo estudo, no que tange aos impactos da precarização do trabalho sobre a saúde do trabalhador, verificou-se que as doenças assumiram formas mais subjetivas, dificultando a associação à atividade laboral. Por exemplo, não era possível afirmar que insônia, obesidade, medo e insegurança são sintomas de trabalhadores precários. No entanto, infere-se que novas doenças ocupacionais acometem os trabalhadores e têm como uma das causas o trabalho inseguro e precário. Outrossim, a convivência entre dois grupos de trabalhadores no mesmo local, dividindo-se entre estatutários e cooperativados, agudizava a sensação de inferioridade em relação à equipe de trabalho, conforme destacado nas respostas dos participantes. Em suma, observou-se que os trabalhadores tinham consciência da sua relação precária e das implicações do seu vínculo na assistência aos demandatários dos serviços de saúde, bem como das consequências desse vínculo em relação a sua satisfação profissional (Costa \& Tambellini, 2009).

Esses dados lançam luz ao fato de que vivências de condições e relações de trabalho precarizadas podem produzir uma série de impactos que vão desde o comprometimento da saúde até prejuízos psicossociais, aspectos que serão tratados na seção seguinte.

\section{Consequências para o trabalhador}

A quebra do "acordo" capital-trabalho, até então próprio do modo de produção fordista, significa, para o trabalhador, a precarização do contrato e das suas condições de trabalho. Dessa forma, uma das consequências mais notórias da flexibilização do mercado de trabalho tem sido marcada pela assimetria na relação entre empregador e empregado, uma vez que esse último deve se responsabilizar pelo ônus causado pelo vigente regime de contratação trabalhista que o desampara. Em tempos neoliberais, tal assimetria se agrava ainda mais, resultando numa relação de forças extremamente desproporcional e desfavorável aos trabalhadores (Druck \& Franco, 2007).

Essa desigualdade de forças pode ser observada, por exemplo, na premência de disponibilidade do indivíduo para sujeitar-se às exigências arbitrárias do emprego, bem como para dedicar tempo e esforço para aprender as particularidades de uma determinada função sem, contudo, ter garantia de que não será dispensado sumariamente, uma vez que, segundo a lógica da flexibilização, o trabalhador é facilmente substituível por outro. A condenação do trabalhador como único responsável por sua empregabilidade (uma vez que os empregados precisam gerir e financiar a própria formação para melhorar sua qualificação e adquirir novas competências para o mercado), por sua permanência no emprego e por seu êxito no trabalho dá-se em condições extremamente adversas criadas pelo capitalismo flexível (Druck, 2011; Kovács, 2003). O incremento em conhecimento na sociedade contemporânea é um critério diferencial para o mercado, uma vez que a modernização produtiva 
toyotista trouxe transformações nas atividades laborais que não dispensam a inventividade e intelecto humanos. E, embora o conhecimento seja elemento perseguido pelas empresas contratantes, não é necessariamente promovido por elas na figura de treinamentos e capacitações para o trabalho, ficando essa tarefa a encargo exclusivo dos contratados, que precisam custear a aquisição do conhecimento, que será utilizado pelas empresas e, às vezes, utilizado unicamente por algumas empresas de ramos especializados.

Apesar de o toyotismo pertencer à mesma lógica de racionalização do trabalho constituinte do taylorismo/fordismo, o que implica considerá-lo uma continuidade destes últimos, ele tenderia, em contrapartida, a surgir com intenções (mais ou menos veladas) de controle do elemento subjetivo da produção capitalista a favor de uma nova subsunção do trabalho ao capital - o que diferencia o modelo flexível de organização e gestão do trabalho dos modelos anteriores. Se o fordismo expropriou e transferiu o saber operário para a esfera da gerência científica, para os níveis de elaboração e planejamento do trabalho, o toyotismo tende a retransferi-lo para a força de trabalho, mas o faz visando apropriar-se crescentemente da sua dimensão intelectual, das suas capacidades cognitivas, procurando envolver mais forte e intensamente a subjetividade operária (Antunes \& Alves, 2004). Mas, essa iniciativa não se encontra livre de contradição, que comparece no paradoxo da multiplicação dos empregos periféricos, mal pagos e com pobre conteúdo de trabalho e da necessidade de se apoiar em recursos humanos qualificados, motivados e integrados, com o objetivo de poder lidar com processos cada vez mais complexos e promover a inovação. Em outras palavras, surge a questão de como conciliar os estatutos dos empregos precários com a mobilização dos recursos humanos como fator prioritário de competitividade (Kovács, 2003). Esse dilema ainda não foi resolvido pela tecnologia de gestão de pessoas nas empresas modernas.

Flexibilidade passou a implicar mudança permanente e continuada, o que evoca fluidez e impossibilidade de compromissos e de relações duráveis, sejam dos trabalhadores para com a empresa contratante, seja destes para com seus pares. A partir da desregulamentação contratual e do afrouxamento das relações sociais de trabalho, outras flexibilizações se tornaram possíveis como as que recaem sobre as jornadas de trabalho, com a criação do banco de horas, ou as que incidem sobre as atribuições de funções e de responsabilidades e os salários variáveis. Não pode ser esquecida a mudança constante de critérios para tudo, a exemplo dos critérios utilizados nas avaliações de desempenho dos trabalhadores, ou dos critérios admissionais/demissionais, carreando uma existência laboral marcada pela transformação acelerada de regras e expectativas. A valorização da polivalência, como atributo indispensável ao trabalhador, por exemplo, surgiu nesse contexto (Seligmann-Silva, 2011).

Os padrões de gestão e organização do trabalho, na busca de maior produtividade a qualquer custo, têm levado a condições extremamente precárias, através da intensificação do trabalho (imposição de metas inalcançáveis, extensão da jornada de trabalho, polivalência), sustentada na gestão pelo medo e desrespeito; na discriminação criada pela terceirização; nas formas de abuso de poder, a exemplo do assédio moral; e na criação de um ambiente de trabalho inseguro e nocivo à saúde pela desconsideração à necessidade de treinamento, esclarecimento sobre riscos e medidas coletivas de prevenção contra acidentes de trabalho (Druck, 2011). Exemplos encontrados no cenário empresarial brasileiro figuram nas pesquisas realizadas na indústria automobilística, na agroindústria canavieira e avícola e no setor de serviços de telemarketing e call center (Antunes, 2014), nos quais foram identificados a generalidade com a qual se aplicam a intensificação do ritmo de trabalho, os baixos salários e as práticas de assédio moral. Arnold e Bongiovi (2013) acrescentam que a ausência de mínimas condições físicas e ambientais de trabalho também contribuem para o crescimento da insegurança percebida e real no trabalho, aumentando o trabalho fora do padrão e contingente, a falta de segurança no trabalho e o estresse e assédio no local de trabalho (Kalleberg, 2009; Rossman, 2013; Vosko, MacDonald \& Campbell, 2009). 
Seligmann-Silva (2011) assevera que o trabalho humano se tornou, cada vez mais, um trabalho dominantemente mental. Porém, o cansaço mental do trabalho intelectual intensificado e a exaustão emocional são veementemente ignorados nos ambientes de trabalho. À medida que a polivalência colabora para o crescimento da sobrecarga de trabalho, o temor de "não dar conta" ou cometer erros se torna aterrorizante, ao tempo em que a fadiga se acumula e o desempenho, inevitavelmente, diminui. Recorrer a substâncias tranquilizantes ou estimulantes e buscar forças nos chamados produtos e alimentos "energéticos" (de mercado, por isso mesmo, aquecidíssimo) se incorporam aos hábitos de muitos sob as formas assumidas pela gestão moderna. Também como resultado da fadiga e da "compressão dos tempos de conviver", a precarização dos vínculos interpessoais e da comunicação significativa alcança a vida familiar, o lazer e as várias modalidades de participação social. A falta de tempo (e disposição) para o usufruto dos interesses particulares e da família colabora para distanciamentos na convivência e afrouxamento dos vínculos, mas não é o único agravante para a "solidão moderna".

A competitividade é atualmente superestimulada nos ambientes de trabalho, de modo a exacerbar cada vez mais o individualismo. O fortalecimento do individualismo facilitou tanto a precarização social quanto a do trabalho, indo concorrer, de maneira importante, também para a precarização da saúde. Amizade, respeito e confiança são apagadas pela mistura de medo e ânsia de sobreviver convivendo com os imperativos de vencer, fortemente apoiados pelo discurso sedutor da excelência, disseminado a partir das grandes empresas. As técnicas desgastantes de gerenciamento, atualmente predominantes dentro dos paradigmas voltados à acumulação flexível e maximização de lucros, ao estimularem a exacerbação da competição entre empregados, concorrem, simultaneamente, para reforçar o individualismo, mitigar a emergência da afeição e promover o aumento do cansaço (Seligmann-Silva, 2011), o que antagoniza com a implementação de políticas de pessoal que demandam o trabalho colaborativo em equipe. Trata-se de mais uma das contradições do universo corporativo contemporâneo que carece de solução para que os objetivos de produtividade e lucratividade possam ser consistentemente alcançados.

O isolamento e a perda de enraizamento, de vínculos, de inserção, de uma perspectiva de identidade coletiva, resultantes da descartabilidade, da desvalorização e da exclusão, são condições que afetam decisivamente a solidariedade de classe, solapando-a pela brutal concorrência que se desencadeia entre os próprios trabalhadores (Druck, 2011). Essa situação contribui para o delineamento de um cenário em que a consciência de classe é cada vez mais mitigada, já que a intermitência de emprego se apresenta como entrave para a integração dos funcionários de uma determinada categoria profissional. Dessa forma, são fragilizados os vínculos de amizade e de companheirismo e a comunicação entre os trabalhadores, que se tornam isolados e sem força de coletivo para reivindicar melhores condições de trabalho e de vida, de modo geral (Franco \& Faria, 2013).

O isolamento de classe, perpetrado como forma de debilitar as relações travadas em ambiente corporativo, suscita desgastes emocionais (a "solidão" do trabalhador moderno) que facilitam o surgimento de adoecimento psicológico e orgânico, como quadros depressivos, esgotamento profissional ou burnout, síndromes paranóides e reação ao estresse agudo, posto que as circunstâncias precarizadas de trabalho, em associação a características individuais, podem deflagrar ou acentuar patologias de diversas ordens. Como exemplo, pode-se apontar o estresse de sobrecarga vivenciado por trabalhadores submetidos a condições de emprego precarizadas, mas que ainda assim devem corresponder ao alto grau de exigência imposto aos trabalhadores, no sentido de potencializar sua produtividade em prol de maiores resultados, sobretudo maiores margens de lucro para o empregador (Hazan, 2013), constituindo motor central da produção de danos à saúde mental dos empregados.

Em síntese, sob o pretexto de elevadas exigências de empregabilidade encaminhadas pelos mercados liberais, permite-se que os indivíduos sejam submetidos, com a anuência do Estado, a 
condições insatisfatórias de trabalho que derivam da política da flexibilização e desregulamentação de direitos sociais, previdenciários e trabalhistas, que agridem não apenas a saúde do trabalhador, mas também a sua cidadania e dignidade, ao passo em que é promovido o enfraquecimento de sindicatos para que a flexibilização dos direitos seja acatada sem que tais organizações ofereçam resistência, alienando os trabalhadores da luta por melhores condições de trabalho e de vida, impelindo-os a aceitarem as parcas opções propostas pelo sistema econômico e a se submeterem a condições de desamparo previdenciário e social para poderem prover meios de subsistência. Nesse sentido, a diminuição do trabalho permanente e estável denota uma deterioração da qualidade dos postos de trabalho e uma maior dificuldade de vislumbrar uma perspectiva de longo prazo para o trabalhador (Tosta, 2009).

\section{Considerações finais}

Nessa sua fase de mundialização, o capital tem desempregado cada vez mais o trabalho estável, substituindo-o por trabalhos precarizados, que se encontram em enorme expansão no mundo industrial e de serviços, bem como nas múltiplas interconexões existentes entre eles (Antunes, 2011). Estabelecem-se contratos de trabalho precários, subcontratação em cascata, configurando uma externalização de riscos e responsabilidades, com redução de salários e de empregos (Gomez \& Thedim-Costa, 1999). Assim, não é mais o padrão da sociedade do pleno emprego, mas o de uma sociedade de desempregados e de formas precárias de trabalho, de emprego e de vida que passa a predominar, até mesmo naqueles países onde se tinha atingido um alto grau de desenvolvimento econômico e social (Druck, 2011).

A precarização dos vínculos empregatícios tem um caráter expansivo que provoca tanto a desestabilização quanto a segmentação do mercado de trabalho e se reflete no agravamento das desigualdades sociais (Linares, 2013). As situações precarizadas de emprego têm consequências individuais e sociais múltiplas, não apenas em nível do consumo e da qualidade de vida, das perspectivas de vida futuras, da proteção social e do acesso a atividades coletivas, mas igualmente em termos de ação e intervenção individual e coletiva, nomeadamente no que respeita à capacidade de defesa de interesses, pois tais práticas precarizantes tendem a golpear ou eliminar (direta ou indiretamente) os direitos de personalidade e as liberdades e garantias do cidadão, quais sejam: liberdade de expressão, direito de defesa coletiva, direito à igualdade de tratamento, direito de constituir família, direito ao descanso e lazer, premissas que integram o conceito de cidadania (Kovács, 2003).

As formas flexíveis de emprego, em grande parte, são inseguras e mal pagas. Por essa razão, em vez de contribuírem para a melhoria da vida familiar, podem provocar graves problemas financeiros e de planejamento futuro, uma vez que a sociedade, em muitos aspectos essenciais, tais como possibilidade de comprar a crédito, de financiar imóvel ou de dispor de aposentadoria, está organizada no pressuposto de que as pessoas tenham emprego. A flexibilização do emprego significa, para além de transferir responsabilidades e riscos para os indivíduos, transferir também para o Estado. $\mathrm{Na}$ impossibilidade de serem os indivíduos a assumirem as responsabilidades pelo enfrentamento aos agravos provocados por doenças, ao perigo de inadimplência na aquisição de habitação e ao cumprimento das exigências normativas para alcançar o direito de recebimento de pensões por aposentadoria, o apelo vai para o Estado (Kovács, 2003), que por sua vez está cada vez mais se retirando desse papel de prestação de assistência social.

O conceito de precarização segue paralelo ao de flexibilização que, por sua vez, altera a regulamentação do mercado de trabalho e a garantia de direitos dos trabalhadores, levando à eliminação das condições de trabalho favoráveis ao trabalhador, deixando-o mais suscetível a 
práticas degradantes (Lima, 2006). Para Vives et al. (2010), as condições de trabalho, tais como as existentes em empregos precários, são os maiores determinantes sociais de desigualdades em quadros de saúde. Precarização do trabalho é um construto integrado a um quadro de relações de poder, as quais são peças-chave na determinação de condições de trabalho e de bem-estar e saúde do trabalhador.

Nesse horizonte, a projeção de cenários sobre o futuro do trabalho depende de um conjunto de condições macroeconômicas, sociais e culturais (Marques, 2013), de modo que a maior difusão de estudos acerca das práticas de precarização de vínculos empregatícios possibilite a criação de movimentos de resistência que demandem a abertura de agendas políticas e sociais voltadas a enfrentar, sem esquivas e de maneira responsável, o problema que se avoluma. Kóvacs (2003) acena com otimismo ao preconizar que os avanços modernos em tecnologia de informação e gestão humana podem promover a melhoria simultânea da produtividade, do emprego e da qualidade de vida, desde que prevaleça uma perspectiva antropocêntrica.

\section{Referências}

Antunes, R. (2008). Adeus ao trabalho? Ensaio sobre as metamorfoses e a centralidade do mundo do trabalho (13a ed.). São Paulo: Cortez.

Antunes, R. (2011). Os modos de ser da informalidade: rumo a uma nova era da precarização estrutural do trabalho? Serviço Social Ë Sociedade, (107), 405-419.

Antunes, R. (2014). Desenhando a nova morfologia do trabalho no Brasil. Estudos Avançados, 28 (81), 39-53.

Antunes, R. \& Alves, G. (2004). As mutações no mundo do trabalho na era da mundialização do capital. Educação Eु Sociedade, 25 (87), 335-351.

Aquino, A. B. C., Moita, D. S., Correa, G. M. \& Souza, K. O. (2014). Fenômeno da precarização e da flexibilização laboral no âmbito da universidade pública brasileira: o caso dos professores substitutos. Athenea Digital, 14 (1), 173-193.

Arnold, D. \& Bongiovi, J. R. (2013). Precarious, informalizing and flexible work: transforming concepts and understanding. American Behavioral Scientist, 57 (3), 289-308.

Barreto, T. R. (2003). A precarização do trabalho e da vida dos novos trabalhadores informais: o trabalho flexível nas ruas de Salvador. Monografia de Bacharelado em Ciências Sociais, Faculdade de Filosofia e Ciências Humanas, Universidade Federal da Bahia, Salvador.

Borges, L. O. \& Yamamoto, O. H. (2004). O mundo do trabalho. In J. C. Zanelli, J. E. Borges-Andrade \& A. V. B. Bastos (Org.), Psicologia, organizações e trabalho no Brasil (pp. 24-62). Porto Alegre: Artmed.

Costa, D. O. \& Tambellini, A. T. (2009). A visibilidade dos escondidos. Physis Revista de Saúde Coletiva, 19 (4), $953-968$.

Druck, M. G. (1999). Terceirização: (des)fordizando a fábrica. Um estudo do complexo petroquímico. São Paulo: Boitempo.

Druck, G. (2011). Trabalho, precarização e resistências: novos e velhos desafios? Caderno CRH, 24 (1), 37-57.

Druck, G. \& Franco, T. (Org.) (2007). A perda da razão social do trabalho: terceirização e precarização. São Paulo: Boitempo.

Franco, T. M. A. \& Faria, M. G. D. (2013). A terceirização/subcontratação do trabalho no Brasil e sua interconexão com a saúde mental no trabalho. In J. J. Ferreira \& L. O. Penido (Org.), Saúde mental no trabalho: coletânea do fórum de saúde e segurança no trabalho do estado de Goiás (pp. 469-486). Goiânia: Cir.

Gomez, C. M. \& Thedim-Costa, S. M. F. (1999). Precarização do trabalho e desproteção social: desafios para a saúde coletiva. Ciência Ė Saúde Coletiva, 4 (2), 411-421.

Hazan, E. M. F. (2013). A falta de estabilidade no emprego e o desemprego como fatores de risco para a saúde mental do trabalhador. In J. J. Ferreira \& L. O. Penido (Org.), Saúde mental no trabalho: coletânea do fórum de saúde e segurança no trabalho do estado de Goiás (pp. 177-200). Goiânia: Cir Gráfica.

Huberman, L. (1986). História da riqueza do homem (21를 ed. revisada). Rio de Janeiro: LTC.

Kalleberg, A. L. (2009). Precarious work, insecure workers: employment relations in transition. American Sociological Review, 74 (1), 1-22. 
Kovács, I. (2003). Reestruturação empresarial e emprego. Perspectiva, 21 (2), 467-494.

Kubo, S. H. \& Gouvêa, M. A. (2012). Análise de fatores associados ao significado do trabalho. Revista de Administração, 47 (4), 540-554.

LaMontagne, A. D. (2010). Precarious employment: adding a health inequalities perspective. Journal of Public Health Policy, 31 (3), 312-317.

Leal, A. L. A. (2008). Bem-estar no trabalho entre docentes universitários: estudo de caso em uma IES pública. Dissertação de Mestrado, Núcleo de Pós-Graduação em Administração, Universidade Federal da Bahia, Salvador.

Lee, C. K. \& Kofman, Y. (2012). The politics of precarity: views beyond the United States. Work and Occupations, 39 (4), 388-408.

Leite, M. P. (2003). Trabalho e sociedade em transformação: mudanças produtivas e atores sociais. São Paulo: Perseu Abramo.

Lima, J. C. (2006). Trabalho, precarização e sindicalismo: os trabalhadores e as cooperativas de trabalho. Estudos de Sociologia, 11 (21), 59-71.

Linares, S. C. G. R. (2013). Análisis comparativo de la precariedad laboral en las tres principales metrópolis mexicanas para el 2010. Facultad de Ciencias Económicas: Investigación y Reflexión, 21 (1), 131-146.

Marques, A. P. P. (2013). Reestruturação produtiva e recomposições do trabalho e emprego: um périplo pelas "novas" formas de desigualdade social. Ciência Ė Saúde Coletiva, 18 (6), 1545-1554.

Nascimento, T. C. C. (2016). Trabalho, emprego e precarização: algumas contribuições. Dissertação de Mestrado, Núcleo de Pós-Graduação e Pesquisa em Psicologia Social, Universidade Federal de Sergipe, São Cristóvão.

Navarro, V. L. \& Padilha, V. (2007). Dilemas do trabalho no capitalismo contemporâneo. Psicologia Ė Sociedade, 19 (especial), 14-20.

Rossman, P. (2013). Establishing rights in the disposable jobs regime. International Journal of Labour Research, 5 (1), 23-40.

Seligmann-Silva, E. (2011). Trabalho e desgaste mental: o direito de ser dono de si mesmo. São Paulo: Cortez.

Souza, N. V. D. O, Santos, D. M. S, Ramos, E. L., Anunciação, C. T., Thiengo, P. C. S., \& Fernandes, M. C. (2010). Repercussões psicofísicas na saúde dos enfermeiros da adaptação e improvisação de materiais hospitalares. Escola Anna Nery, 14 (2), 236-243.

Standing, G. (2014). O precariado e a luta de classes. Revista Crítica de Ciências Sociais, 103, 924.

Tosta, T. L. D. (2008). Antigas e novas formas de precarização do trabalho: o avanço da flexibilização entre profissionais de alta escolaridade. Tese de Doutorado, Departamento de Sociologia, Universidade de Brasília, Brasília.

Tosta, T. L. D. (2009). Um novo perfil de precarização do trabalho? In Resumos de comunicações científicas do XIV Congresso Brasileiro de Sociologia. Rio de Janeiro: Sociedade Brasileira de Sociologia.

Verma, A. \& Gomes, A. V. M. (2014). Labor market flexibility and trajectories of development: lessons from Brazil, India and China. Business $\mathcal{E}$ Management Practices, 50 (1), 51-74.

Vives, A., Amable, M., Ferrer. M., Moncada, S., Llorens, C., Muntaner, C., Benavides, F. G. \& Benach, J. (2010). The Employment Precariousness Scale (EPRES): psychometric properties of a new tool for epidemiological studies among waged and salaried workers. Occupational $\mathbb{E}$ Environmental Medicine, 67 (8), 548-555.

Vosko, L. F., MacDonald, M. \& Campbell, I. (Ed.) (2009). Gender and the contours of precarious employment. London: Routledge.

\section{Endereço para correspondência}

marleymeloaraujo@gmail.com, katiarsm@msn.com
Enviado em: 22/10/2015

Revisado em: 05/01/2017

Aprovado em: 27/09/2017 